\title{
Episodic palpitations in pheochromocytoma
}

\author{
Lee S. Roth MD, Janis Nicholson MD
}

Previously published at www.cmaj.ca

A

54-year-old man presented with an 8-week history of episodic palpitations accompanied by chest pain and headache. He had no sweating with the episodes. Investigations included 24-hour urine collection for the presence of metanephrines. One month later, while awaiting the results of the investigations, the patient went to the emergency department with a recurrence of the palpitations. He was initially found to be in normal sinus rhythm with a serum cardiac troponin I level of 0.26 (normal $<0.03) \mu \mathrm{g} / \mathrm{L}$. During cardiac monitoring, he experienced an episode of palpitations with a peak heart rate of 186 beats/min in supraventricular tachycardia. His blood pressure rose from a baseline of $100 / 58 \mathrm{~mm} \mathrm{Hg}$ to $172 / 76$ $\mathrm{mm} \mathrm{Hg}$ and peaked at 262/172 $\mathrm{mm} \mathrm{Hg}$. The arrhythmia resolved spontaneously with the patient's blood pressure dropping to $92 / 56 \mathrm{~mm} \mathrm{Hg}$.

On two 24-hour urine collections, urinary metanephrine levels were elevated at 7.1 and 10.3 (normal 0-1.7) $\mu \mathrm{mol} / \mathrm{day}$. The patient's urinary metanephrine-to-creatinine ratios were 0.855 and 0.972 (normal < 0.354). An $\alpha$-receptor antagonist was started and titrated to control the patient's blood pressure levels. A $\beta$-receptor antagonist was added once adequate alpha blockade had been achieved. A computed tomography scan without contrast performed 2 weeks later showed a $4-\mathrm{cm}$ mass on the left adrenal gland (Figure 1). A laparoscopic adrenalectomy was performed 1 month later. Pathologic examination of the adrenal mass after resection was consistent with the diagnosis of pheochromocytoma.

Pheochromocytoma is a catecholamine-secreting neuroendocrine tumour usually found in the adrenal gland. It is the cause of hypertension in approximately $0.2 \%$ of patients with hypertension. ${ }^{1}$ Classic symptoms, such as the triad of episodic headache, sweating and tachycardia, are typical. Episodic hypertension occurs in about half of patients with pheochromocytoma. ${ }^{1}$ Diagnosis is usually made on the basis of ele-

From the Division of Gastroenterology (Roth), Department of Medicine London Health Sciences Centre, London, Ont., and the Huron Perth Healthcare Alliance (Nicholson), Department of Internal Medicine, Stratford General Hospital, Stratford, Ont.

Cite as CMAJ 2009. DOI:10.1503/cmaj.090124

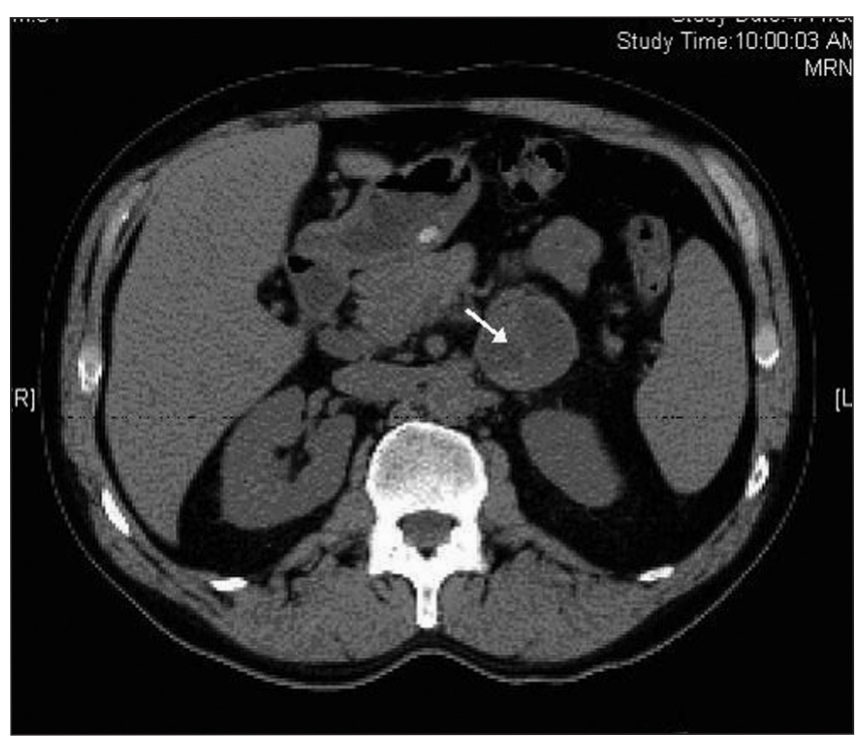

Figure 1: Computed tomography scan of the abdomen of a 54year-old man with pheochromocytoma, showing a 4-cm mass (arrow) on the left adrenal gland.

vated catecholamine and metanephrine levels in the serum or 24-hour urine collections. The ratio of urinary metanephrines to urinary creatinine may be more diagnostically accurate because it controls for incorrect 24-hour urine collections. ${ }^{2}$ Treatment includes $\beta$-receptor antagonists once adequate $\alpha$-blockade has been achieved with an $\alpha$-receptor antagonist. This sequencing prevents unopposed $\alpha$-stimulation that may worsen the hypertension. ${ }^{1}$ Definitive therapy involves surgical resection. Rates of complication are similar between open and laparoscopic adrenalectomy (about 27\%). ${ }^{3}$

\section{REFERENCES}

1. Goldman L, Ausiello D. Cecil Textbook of Medicine. 22nd ed. Philadelphia (PA): Saunders; 2004. p. 1420.

2. Heron E, Chatellier G, Billaud E, et al. The urinary metanephrine-to-creatinine ratio for the diagnosis of pheochromocytoma. Ann Intern Med 1996;125:300-3.

3. Humphrey R, Gray D, Pautler S, et al. Laparoscopic compared with open adrenalectomy for resection of pheochromocytoma: a review of 47 cases. Can J Surg 2008;51:276-80. 